\title{
SIMILARIDADE FLORÍSTICA DAS FLORESTAS SUPEROMONTANAS NO DOMÍNIO ATLÂNTICO, BRASIL ${ }^{1}$
}

Amanda Koche Marcon², Ana Carolina da Silva ${ }^{3}$, Pedro Higuchi ${ }^{3}$, Francieli de Fátima Missio², Tiago de Souza Ferreira² ${ }^{2}$ Bruna Salami², Angelica Dalla Rosa ${ }^{4}$, Marco Antonio Bento ${ }^{4}$ e Fernando Buzzi Júnior ${ }^{4}$

\begin{abstract}
RESUMO - Este estudo teve como objetivos avaliar a similaridade florística do componente arbóreo de 39 remanescentes de florestas superomontanas no domínio atlântico, Brasil, e analisar a influência de variáveis geográficas e climáticas sobre os padrões observados. Foi utilizada uma matriz binária de presença e ausência das espécies arbóreas compiladas dos 39 levantamentos florísticos e fitossociológicos. Para conhecer a relação da composição florística das áreas com variáveis ambientais e espaciais, foram extraídas as coordenadas geográficas e os dados climáticos de cada área. Com o objetivo de avaliar a similaridade florística dos remanescentes, foi utilizado um dendrograma e, para determinar a influência de variáveis ambientais e espaciais sobre os padrões florísticos, foi utilizada a análise multivariada NMDS. O dendrograma e a NMDS demonstraram a formação de agrupamentos, predominantemente entre remanescentes localizados em uma mesma unidade fitogeográfica. Observou-se a existência de um gradiente ambiental ligado às condições climáticas. Em áreas com maiores valores de sazonalidade térmica, amplitude térmica anual, precipitação, latitude e longitude, ocorreram florestas superomontanas com matriz ombrófila e, em áreas com maiores valores de temperatura média, amplitude térmica diária, isotermalidade, sazonalidade da precipitação e temperatura mínima no mês mais frio, ocorreram predominantemente florestas com matriz estacional.
\end{abstract}

Palavras-chave: Fitogeografia; Comparação florística; NMDS.

\section{FLORISTIC SIMILARITY OF UPPER MONTANE FORESTS IN ATLANTIC DOMAIN, BRAZIL}

\begin{abstract}
This study investigated the floristic similarity of the tree component of 39 upper montane forest fragments in Atlantic domain, Brazil, and the influence of geographic and climatic variables on the patterns observed. It was created a binary matrix of presence and absence of the tree species compiled from the 39 floristic and phytosociological survey. For the relationship of the floristic composition of the areas with the environmental and spatial variables, the geographic coordinates and climate data of each area were extracted. The floristic similarity of the fragments was measured using a dendrogram and for determination of environmental and spatial variables influence on floristic patterns, a nonmetric multidimensional scaling analysis (NMDS) was used. The dendrogram analysis and the NMDS showed the formation of clusters, predominantly among fragments located in the same phytogeographic unit. The existence of an environmental gradient based on the climatic conditions was observed. In areas with higher thermal seasonality, annual temperature range, precipitation, latitude and longitude, upper montane forests with rain forest matrix occurred, and in areas with higher average temperature, daily temperature range, isothermality, seasonality of precipitation and minimum temperature in the coldest month, upper montane forests with seasonal matrix occurred.
\end{abstract}

Keywords: Phytogeography; Floristic comparison; NMDS.

\footnotetext{
${ }^{1}$ Recebido em 21.08.2013 aceito para publicação em 24.07.2014.

${ }^{2}$ Programa de Pós-Graduação em Engenharia Florestal, Universidade do Estado de Santa Catarina (UDESC), Brasil. E-mail: <amandamarcon@yahoo.com.br>,<franmissio@yahoo.com.br>,<tiagoferreira@florestal.eng.br>e <brunaflorestal@yahoo.com.br>. ${ }^{3}$ Departamento de Engenharia Florestal, UDESC, Brasil. E-mail: <carol_sil4@yahoo.com.br>e <higuchip@gmail.com>. ${ }^{4}$ Graduanda em Engenharia Florestal, UDESC, Brasil. E-mail: <angelica.dalla.rosa@hotmail.com>, <marco_a_bento@hotmail.com> e <buzzifjr@hotmail.com>.
} 


\section{INTRODUÇÃO}

Ecossistemas montanhosos abrigam espécies de alto valor ecológico e possuem altos níveis de endemismo, abrangendo cerca de $27 \%$ da superfície terrestre e, por possuírem nascente de rios, são responsáveis por suprir as necessidades de água doce de mais da metade da humanidade (CBD, 1992). De forma semelhante à grande parte da vegetação brasileira, houve a redução de sua área devido a pressões como fogo e mudanças de cobertura da terra, sendo encontrada, atualmente, em fragmentos (CBD, 1992; OLIVEIRA FILHO et al., 2004). Nesses locais, a vegetação é diferente da encontrada em pisos inferiores de altitude, sendo as árvores, muitas vezes, tortuosas e de porte reduzido, com folhas pequenas e coriáceas, e há menor riqueza de angiospermas (WEBSTER, 1995). Ainda, quando estão sob constante nevoeiro, elas são denominadas florestas nebulares (FALKENBERG, 2003).

No Brasil, as florestas de maiores altitudes ocorrem nas cadeias montanhosas, estando, no Sul, presentes em altitudes entre 700 e $1.600 \mathrm{~m}$ e ocupando as altas montanhas do complexo da Serra do Mar e a borda do planalto da Serra Geral (FALKENBERG; VOLTOLINI, 1995), e, na região Nordeste, em serras isoladas e disjuntas da porção sul da Chapada Diamantina (NASCIMENTO et al., 2010). De acordo com a classificação do IBGE (2012), essa floresta é denominada Alto-Montana e está presente nas formações de Floresta Ombrófila Densa, que possui florística representada por famílias de ampla dispersão geográfica, e na Floresta Ombrófila Mista, que possui presença comum de Araucaria angustifolia (Bertol.) Kuntze e Podocarpus lambertii Klotzsch ex Endl. No entanto, Oliveira Filho (2009) propôs que as florestas de maior altitude estão presentes nas formações Ombrófilas e Estacionais, em altitudes superiores a 900 m na região subtropical e acima de $1.000 \mathrm{~m}$ na região tropical, sendo classificadas pelo autor como superomontanas.

As florestas superomontanas, por ocorrerem em diferentes regiões fitofisionômicas, podem possuir influência dessas em suas composições florísticas. Estudos comparativos entre fragmentos florestais vêm demonstrando que as semelhanças florísticas encontradas entre as áreas se devem, em grande parte, à influência do domínio vegetacional em que estão inseridas (van den BERG; OLIVEIRA FILHO, 2000; RIBAS et al., 2003). Os chamados "efeitos de matriz" possuem forte impacto na configuração da paisagem sobre a diversidade local, visto que a proximidade geográfica aumenta a similaridade entre os locais à medida que há maiores semelhanças ambientais, e, sobretudo, climáticas (DAUBER et al., 2003). No entanto, outros fatores como a altitude, diferentes históricos de perturbação, regeneração e disponibilidade de água e nutrientes do solo provavelmente estão relacionados às particularidades ecológicas de cada trecho (van den BERG; OLIVEIRA FILHO, 2000). Assim, para verificar se há similaridade florística entre os remanescentes de florestas superomontanas do domínio atlântico do Brasil, embora cada um possua influência da matriz florística da região onde está inserido, este estudo teve como objetivo avaliar a similaridade florística do componente arbóreo de remanescentes dessas florestas e a influência de variáveis geográficas e climáticas sobre os padrões observados.

\section{MATERIAL E MÉTODOS}

Para realizar a comparação florística, foi utilizada uma lista de espécies arbóreas compilada de 39 levantamentos florísticos e fitossociológicos de florestas classificadas como superomontanas, de acordo com a classificação de Oliveira Filho (2009), do domínio atlântico, Brasil (Tabela 1). Desses, um estudo foi realizado no Rio Grande do Sul (RS), sete em Santa Catarina (SC), 11 no Paraná (PR), dois em São Paulo (SP), seis em Minas Gerais (MG) e 12 na Bahia (BA) (Figura 1). As informações referentes às espécies passaram por uma revisão a respeito do hábito, selecionando somente as espécies arbóreas, a nomenclatura e as sinonímias botânicas, considerandose o nome atual das espécies de acordo com a Lista de Espécies da Flora do Brasil (2013), e não foram incluídas na análise espécies identificadas até o nível de família ou gênero. Buscou-se, assim, padronizar os estudos. No entanto, devido ao pequeno número de estudos em florestas superomontanas, foram incluídos estudos com diferentes metodologias de amostragem, que poderiam gerar um viés estatístico. Porém, considerase que, para os objetivos propostos e para a escala espacial utilizada, o valor da informação florística acrescida pela inclusão de remanescentes com metodologias distintas é maior do que o custo gerado devido ao possível viés estatístico. A lista florística foi organizada em uma matriz binária de presença e ausência das espécies nas 39 áreas. 
Tabela 1 - Levantamentos florísticos e fitossociológicos de fragmentos de florestas superomontanas no domínio atlântico, Brasil.

Table 1 - Floristic and phytosociological surveys of upper montane forest fragments in Atlantic domain, Brazil.

\begin{tabular}{|c|c|c|c|c|c|c|}
\hline Sigla-UF & Localidade-Município & Autor & Alt. & m.a. & n.i. & $\mathbf{N}$ \\
\hline SRO-RS & $\begin{array}{l}\text { Serra da Rocinha-São } \\
\text { José dos Ausentes, com } \\
\text { trechos em SC: Timbé } \\
\text { do Sul e Meleiro }\end{array}$ & Falkenberg, 2003 & 1200 & Excursões & $\begin{array}{l}\text { Fanerógamos } \\
\text { férteis }\end{array}$ & 61 \\
\hline URU-SC & $\begin{array}{l}\text { Fazenda Nascentes- } \\
\text { Urupema }\end{array}$ & $\begin{array}{l}\text { Martins-Ramos } \\
\text { et al., } 2010\end{array}$ & 1425 & Excursões & $\begin{array}{c}\text { Arbóreas e } \\
\text { arborescentes }\end{array}$ & 58 \\
\hline ERM-SC & $\begin{array}{l}\text { Estâncias Ribeiro e } \\
\text { Machado-Bom Jardim } \\
\text { da Serra }\end{array}$ & Eskuche, 2007 & 1319 & - & - & 28 \\
\hline FAR-SC & Farofa-Painel & Higuchi et al., 2013 & 1399 & Parcelas & $\mathrm{CAP} \geq 15,7 \mathrm{~cm}$ & 49 \\
\hline SCB-SC & $\begin{array}{l}\text { Serra do Corvo } \\
\text { Branco-Urubici }\end{array}$ & Falkenberg, 2003 & 1400 & Excursões & $\begin{array}{l}\text { Fanerógamos } \\
\text { férteis }\end{array}$ & 83 \\
\hline MI-SC & Morro da Igreja-Urubici & Falkenberg, 2003 & 1860 & Excursões & $\begin{array}{l}\text { Fanerógamos } \\
\text { férteis }\end{array}$ & 55 \\
\hline SRR-SC & $\begin{array}{l}\text { Serra do Rio do } \\
\text { Rastro-Bom Jardim } \\
\text { da Serra }\end{array}$ & Falkenberg, 2003 & 1400 & Excursões & Fanerógamos férteis & 91 \\
\hline MN-SC & Mundo Novo-Urubici & Presente estudo & 1600 & Parcelas & $\mathrm{CAP} \geq 15,7 \mathrm{~cm}$ & 32 \\
\hline MMC-PR & $\begin{array}{l}\text { Morro Mãe Catira- } \\
\text { Morretes }\end{array}$ & Koehler et al., 2002 & 1590 & Parcelas & $\mathrm{CAP} \geq 10 \mathrm{~cm}$ & 19 \\
\hline MAN-PR & $\begin{array}{l}\text { Morro Anhangava1- } \\
\text { Quatro Barras }\end{array}$ & Roderjan, 1994 & 1460 & Parcelas & $\mathrm{CAP} \geq 10 \mathrm{~cm}$ & 24 \\
\hline MAG-PR & $\begin{array}{l}\text { Morro Anhangava2- } \\
\text { Bocaiuva do Sul }\end{array}$ & Portes et al., 2001 & 1420 & Parcelas & $\mathrm{CAP} \geq 10 \mathrm{~cm}$ & 24 \\
\hline PPM-PR & $\begin{array}{l}\text { Parque Est. Pico } \\
\text { do Morubi-Morretes }\end{array}$ & Rocha, 1999 & 1380 & Parcelas & $\mathrm{CAP} \geq 10 \mathrm{~cm}$ & 27 \\
\hline MVG-PR & $\begin{array}{l}\text { Morro do Vigia- } \\
\text { Morretes }\end{array}$ & Koehler et al., 2002 & 1545 & Parcelas & $\mathrm{CAP} \geq 10 \mathrm{~cm}$ & 25 \\
\hline SRS-PR & $\begin{array}{l}\text { Serra do Salto-São } \\
\text { José dos Pinhais }\end{array}$ & Koehler et al., 2002 & 1390 & Parcelas & $\mathrm{CAP} \geq 10 \mathrm{~cm}$ & 20 \\
\hline MAR-PR & $\begin{array}{l}\text { Morro Araçatuba- } \\
\text { Guaratuba }\end{array}$ & Koehler et al., 2002 & 1610 & Parcelas & $\mathrm{CAP} \geq 10 \mathrm{~cm}$ & 17 \\
\hline IBI-PR & $\begin{array}{l}\text { Serra do Ibitiratiquire- } \\
\text { Campina Grande do Sul }\end{array}$ & $\begin{array}{l}\text { Scheer e } \\
\text { Mocochinski, } 2009\end{array}$ & 1887 & Excursões & Vasculares férteis & 45 \\
\hline SIG-PR & $\begin{array}{l}\text { Serra da Igreja- } \\
\text { Morretes }\end{array}$ & $\begin{array}{l}\text { Scheer e } \\
\text { Mocochinski, } 2009\end{array}$ & 1376 & Excursões & Vasculares férteis & 39 \\
\hline SPR-PR & $\begin{array}{l}\text { Serra da Prata- } \\
\text { Morretes }\end{array}$ & $\begin{array}{l}\text { Scheer e } \\
\text { Mocochinski, } 2009\end{array}$ & 1502 & Excursões & Vasculares férteis & 35 \\
\hline SGI-PR & $\begin{array}{l}\text { Serra Gigante- } \\
\text { Guaraqueçaba }\end{array}$ & $\begin{array}{l}\text { Scheer e } \\
\text { Mocochinski, } 2009\end{array}$ & 1069 & Excursões & Vasculares férteis & 45 \\
\hline MOV-MG & $\begin{array}{l}\text { Monte Verde- } \\
\text { Camanducaia }\end{array}$ & Meireles et al., 2008 & 1940 & Parcelas & $\mathrm{CAP} \geq 15 \mathrm{~cm}$ & 60 \\
\hline MAT-MG & Matão-Camanducaia & $\begin{array}{l}\text { França e } \\
\text { Stelmann, } 2004\end{array}$ & 1900 & Parcelas & $\mathrm{CAP} \geq 15 \mathrm{~cm}$ & 58 \\
\hline CAR-MG & $\begin{array}{l}\text { Cachoeira do Rio Grande- } \\
\text { Bocaina de Minas }\end{array}$ & $\begin{array}{l}\text { Carvalho } \\
\text { et al., } 2005\end{array}$ & 1210 & Parcelas & $\mathrm{DAP} \geq 5 \mathrm{~cm}$ & 212 \\
\hline SNG-MG & Serra Negra-Ibitipoca & Valente et al., 2011 & 1300 & Parcelas & $\mathrm{CAP} \geq 10 \mathrm{~cm}$ & 77 \\
\hline PCA-MG & Poços de Caldas & Costa et al., 2011 & 1575 & Parcelas & $\mathrm{DAP} \geq 5 \mathrm{~cm}$ & 174 \\
\hline CPC-MG & $\begin{array}{l}\text { Chapada dos } \\
\text { Perdizes-Carrancas }\end{array}$ & $\begin{array}{l}\text { Oliveira-Filho } \\
\text { et al., } 200\end{array}$ & 1440 & Parcelas & $\mathrm{DAP} \geq 5 \mathrm{~cm}$ & 211 \\
\hline CAJ-SP & Campos do Jordão & $\begin{array}{l}\text { Pereira-Silva } \\
\text { et al., } 2007\end{array}$ & 1882 & Excursões & Arbóreas & 35 \\
\hline CJO-SP & Campos do Jordão II & Valeriano, 2010 & 1500 & Parcelas & $\mathrm{CAP} \geq 5 \mathrm{~cm}$ & 77 \\
\hline GAI-BA & Gaia da Mata- & Nascimento & 1350 & Excursões & $\mathrm{CAP} \geq 8 \mathrm{~cm}$ & 57 \\
\hline
\end{tabular}


Tabela 1 - Cont.

Table 1 - Cont

\begin{tabular}{|c|c|c|c|c|c|c|}
\hline GMB-BA & $\begin{array}{l}\text { Rio de Contas } \\
\text { Mata do Gamba- } \\
\text { Rio de Contas }\end{array}$ & $\begin{array}{l}\text { et al., } 2010 \\
\text { Nascimento } \\
\text { et al., } 2010\end{array}$ & 1500 & Excursões & $\mathrm{CAP} \geq 8 \mathrm{~cm}$ & 37 \\
\hline СРA-BA & $\begin{array}{l}\text { Mata do Caminho- } \\
\text { Rio de Contas }\end{array}$ & $\begin{array}{l}\text { Nascimento } \\
\text { et al., } 2010\end{array}$ & 1500 & Excursões & $\mathrm{CAP} \geq 8 \mathrm{~cm}$ & 46 \\
\hline CHQ-BA & $\begin{array}{l}\text { Mata do Chiquinho- } \\
\text { Rio de Contas }\end{array}$ & $\begin{array}{l}\text { Nascimento } \\
\text { et al., } 2010\end{array}$ & 1400 & Excursões & $\mathrm{CAP} \geq 8 \mathrm{~cm}$ & 45 \\
\hline CCF-BA & $\begin{array}{l}\text { Mata do Caminho } \\
\text { Cafundó-Rio de Contas }\end{array}$ & $\begin{array}{l}\text { Nascimento } \\
\text { et al., } 2010\end{array}$ & 1500 & Excursões & $\mathrm{CAP} \geq 8 \mathrm{~cm}$ & 38 \\
\hline CFD-BA & $\begin{array}{l}\text { Mata do Cafundó- } \\
\text { Rio de Contas }\end{array}$ & $\begin{array}{l}\text { Nascimento } \\
\text { et al., } 2010\end{array}$ & 1550 & Excursões & $\mathrm{CAP} \geq 8 \mathrm{~cm}$ & 51 \\
\hline CMP-BA & $\begin{array}{l}\text { Mata da Campinha } \\
\text { Estreita-Rio de Contas }\end{array}$ & $\begin{array}{l}\text { Nascimento } \\
\text { et al., } 2010\end{array}$ & 1600 & Excursões & $\mathrm{CAP} \geq 8 \mathrm{~cm}$ & 52 \\
\hline SUB-BA & $\begin{array}{l}\text { Mata da Subida- } \\
\text { Rio de Contas }\end{array}$ & $\begin{array}{l}\text { Nascimento } \\
\text { et al., } 2010\end{array}$ & 1650 & Excursões & $\mathrm{CAP} \geq 8 \mathrm{~cm}$ & 45 \\
\hline SVN-BA & $\begin{array}{l}\text { Fragmento Silvano- } \\
\text { Rio de Contas }\end{array}$ & $\begin{array}{l}\text { Nascimento } \\
\text { et al., } 2010\end{array}$ & 1600 & Excursões & $\mathrm{CAP} \geq 8 \mathrm{~cm}$ & 45 \\
\hline CBC-BA & $\begin{array}{l}\text { Mata do Cabecinha- } \\
\text { Rio de Contas }\end{array}$ & $\begin{array}{l}\text { Nascimento } \\
\text { et al., } 2010\end{array}$ & 1650 & Excursões & $\mathrm{CAP} \geq 8 \mathrm{~cm}$ & 43 \\
\hline OSR-BA & $\begin{array}{l}\text { Fragmento Osório- } \\
\text { Rio de Contas }\end{array}$ & $\begin{array}{l}\text { Nascimento } \\
\text { et al., } 2010\end{array}$ & 1600 & Excursões & $\mathrm{CAP} \geq 8 \mathrm{~cm}$ & 45 \\
\hline CIG-BA & $\begin{array}{l}\text { Mata do Cigano- } \\
\text { Rio de Contas }\end{array}$ & $\begin{array}{l}\text { Nascimento } \\
\text { et al., } 2010\end{array}$ & 1750 & Excursões & $\mathrm{CAP} \geq 8 \mathrm{~cm}$ & 49 \\
\hline
\end{tabular}

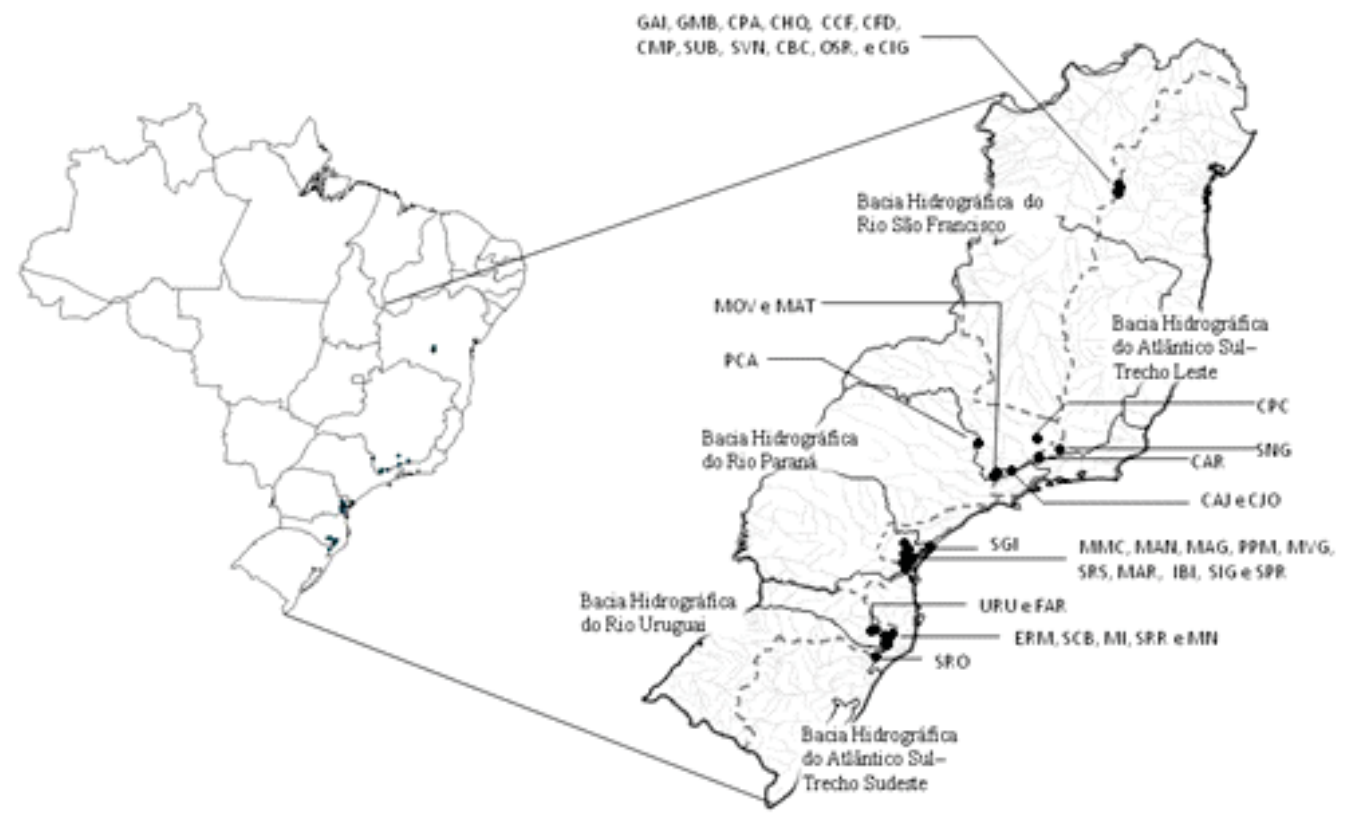

Figura 1 - Localização dos fragmentos de florestas superomontanas no domínio atlântico, Brasil, utilizados na comparação florística.

Figure 1 - Location of the upper montane forest fragments in Atlantic domain, Brazil, used in the floristic comparison.

Revista Árvore, Viçosa-MG, v.38, n.5, p.787-797, 2014 
Para conhecer a relação da composição florística com variáveis ambientais e espaciais, foram utilizados dados climáticos (1950-2000) e coordenadas geográficas de cada área. As coordenadas geográficas, em graus, foram extraídas das publicações citadas, e os dados climáticos, do banco de dados WORLDCLIM(HIJMANS et al., 2005): temperatura média anual (b1), média da amplitude térmica diária (b2), isotermalidade (b3), sazonalidade térmica (b4), temperatura máxima no mês mais quente (b5), temperatura mínima no mês mais frio (b6), amplitude térmica anual (b7), temperatura média no trimestre mais úmido (b8), temperatura média no trimestre mais úmido (b9), temperatura média no trimestre mais quente (b10), temperatura média no trimestre mais frio (b11), precipitação (pp) total anual (b12), pp no mês mais úmido (b13), pp no mês mais seco (b14), sazonalidade da pp (b15), pp total no trimestre mais úmido (b16), pp total no trimestre mais seco (b17), pp total no trimestre mais quente (b18) e pp total no trimestre mais frio (b19).

Foram verificadas as espécies mais frequentes nos 39 levantamentos. Para avaliar a relação florística dos remanescentes, foi utilizado um dendrograma, utilizando o índice de Sorensen como medida de distância e o algoritmo UPGMA como método de ligação. Para determinação dos agrupamentos e da influência de variáveis ambientais e espaciais sobre os padrões florísticos, foi utilizada a análise multivariada NMDS (Escalonamento multidimensional não métrico), empregando duas dimensões $(k=2)$ (MINCHIN, 1987) e utilizando o índice de Sorensen, como medida de similaridade. A adequabilidade da ordenação para a interpretação foi avaliada por meio do valor de estresse. As variáveis ambientais e espaciais foram ajustadas e inseridas em vetores a posteriori à ordenação, sendo utilizadas 1.000 permutações e excluídas as variáveis de baixa significância $(p>0,01)$. As análises foram realizadas no programa $R$ ( $R$ DEVELOPMENT CORE TEAM, 2010), utilizando a biblioteca Vegan (OKSANEN et al., 2009).

\section{RESULTADOS}

Foram encontradas 639 espécies nas 39 listagens analisadas, com média de 57 espécies por remanescente, com variação entre 17 e 212 espécies. Blepharocalyx salicifolius (Kunth) O. Berg e Myrcia guianensis (Aubl.) DC. foram as espécies encontradas com maior frequência, estando presentes em 74\% das áreas e possuindo ampla distribuição geográfica no domínio atlântico. Outras espécies com ampla distribuição foram: Myrsine umbellata Mart. (67\% das áreas); Drimys brasiliensis Miers (64\%); Prunus myrtifolia (L.) Urb. (61\%); Cabralea canjerana (Vell.) Mart. (51\%); Clethra scabra Pers. (49\%); Ilex microdonta Reissek (49\%); e Persea major (Nees) L.E. Kopp (49\%).

As 39 áreas analisadas formaram agrupamentos no dendrograma, e somente o remanescente do RS não se agrupou, sendo distinto dos demais, com dissimilaridade acima de 90\% (Figura 2). Após a separação do RS no dendrograma, a próxima separação ocorreu, com dissimilaridade em torno de $90 \%$, entre o agrupamento de remanescentes em matrizes com vegetação ombrófila e os presentes em matrizes com vegetação predominante estacional. As formações ombrófilas estão representadas pelos fragmentos do PR, SC, SP e MG (áreas em Camanducaia, as de maior altitude estudadas em MG, com altitudes acima de $1.900 \mathrm{~m})$. Os remanescentes com matriz predominante estacional estão representados pelos fragmentos da BA e demais áreas de MG (com altitudes inferiores a $1.900 \mathrm{~m}$ ). Dentro do grupo de ombrófilas, há a separação, com valor de dissimilaridade acima de $80 \%$, dos remanescentes paranaenses, que se distinguiram do agrupamento formado por remanescentes de SC, SP e MG (Camanducaia). No agrupamento das matrizes predominantes estacionais, com dissimilaridade acima de $80 \%$, ocorre a separação do grupo dos fragmentos da BA com o grupo dos remanescentes de MG (os com altitude inferior a $1.900 \mathrm{~m}$ ).

Os agrupamentos encontrados na NMDS (Figura 3) confirmam os resultados do dendrograma. Nela, pode ser observada a formação de quatro grandes agrupamentos: o Grupo 1, localizado na parte esquerda superior da ordenação e apresentando-se mais coeso, foi formado pelos remanescentes localizados no Estado do Paraná. O Grupo 2, localizado de forma mais dispersa na parte esquerda inferior da ordenação, foi formado pelas florestas dos Estados de Santa Catarina, São Paulo e Minas Gerais (Camanducaia). O Grupo 3, que está no lado direito superior, apresentando-se mais coeso, foi formado pelos remanescentes da Bahia. O Grupo 4, no lado direito inferior, foi formado pelos demais fragmentos de Minas Gerais (com altitude inferior a $1.900 \mathrm{~m}$ ). De forma mais isolada, o fragmento do Rio Grande do Sul destaca-se distante dos demais remanescentes, abaixo e no centro do diagrama, não 


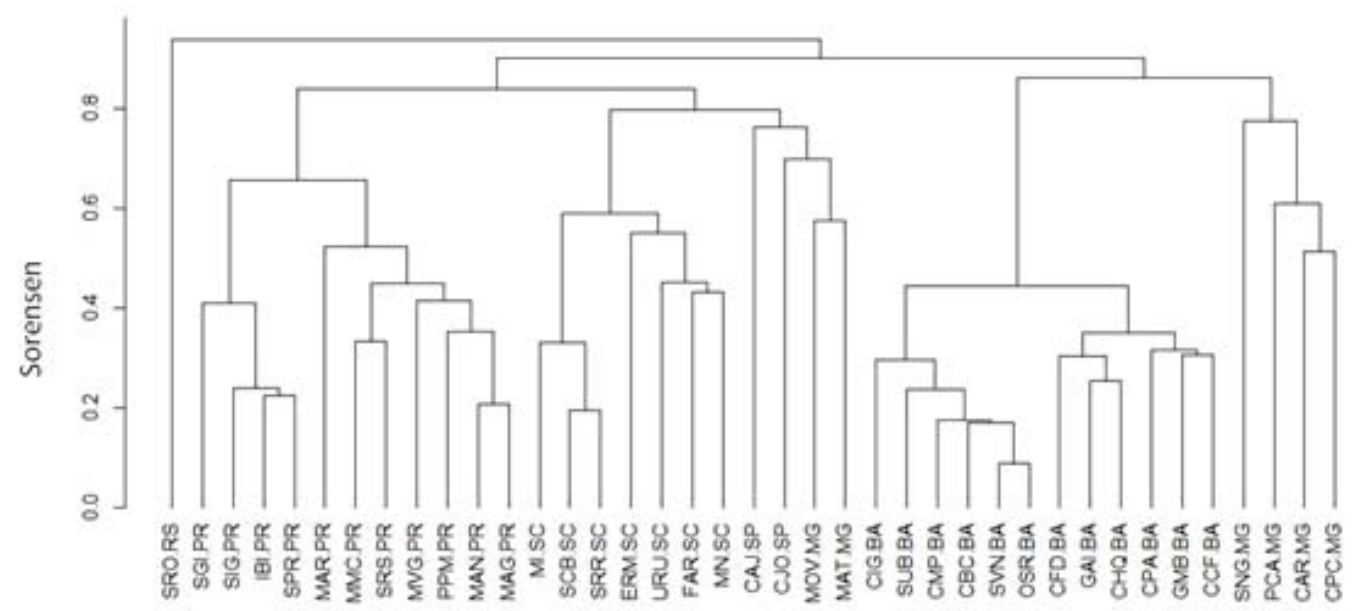

Figura 2 - Dendrograma de ordenação de remanescentes de florestas superomontanas, localizados no domínio atlântico, Brasil. O significado das siglas se encontra na Tabela 1.

Figure 2 - Ordination dendrogram of of upper montane forest fragments in Atlantic domain, Brazil. The abbreviations are in Table 1.

sendo considerado parte de nenhum agrupamento. O valor de estresse da análise NMDS foi de 13,20\% ( $p \leq 0,01)$, que corresponde a uma variância explicada de $86,80 \%$, indicando que o diagrama é adequado para interpretação.

Observa-se, na Figura 3, uma partição ao longo do eixo 1 da ordenação NMDS ligada a um gradiente ambiental, em que, à esquerda, se tem um grande grupo das florestas com matriz ombrófila (PR, SC, SP e MGCamanducaia). À direita, as florestas estão em matriz predominantemente estacional, com exceção das florestas de MG de Ibitipoca (SNG-MG) e Bocaina de Minas (CAR-MG), que estão em matriz ombrófila, porém em áreas com influência estacional (próximas a ecótonos). Os remanescentes localizados no lado esquerdo da ordenação (florestas ombrófilas) ocorreram em áreas de maior sazonalidade térmica (b4), maior amplitude térmica anual (b7), maior umidade e precipitação (b12, b14, b17 e b19) e maior latitude (Y) e longitude (X). Os remanescentes localizados no lado direito da ordenação (florestas predominantemente em matrizes estacionais) apresentaram maiores temperaturas médias, tanto no trimestre mais úmido quanto no mais frio (b9 eb11), maior temperatura média anual (b1), maior amplitude térmica diária (b2), maior isotermalidade (b3), maior sazonalidade da precipitação (b15) e maior temperatura mínima no mês mais frio (b6).
Ao longo do eixo 2 da NMDS ocorreram as variações internas de cada grupo. No grupo das ombrófilas, observou-se a separação das formações ombrófilas mista (SC e SP, abaixo no diagrama, embora as áreas de Camanducaia, MG, classificadas como densas, tenham se agrupado às mistas) e densa (PR, acima no diagrama). No grupo das estacionais, houve separação no eixo 2 entre os remanescentes da BA e os de MG, em altitude abaixo de $1.900 \mathrm{~m}$.

\section{DISCUSSÃO}

Em florestas superomontanas, devido à restrição ambiental, espera-se baixa riqueza, como foi encontrada na maioria dos estudos. Porém, a alta riqueza encontrada em alguns remanescentes de MG, que ultrapassaram 100 espécies contabilizadas, pode ser explicada pelas características intrínsecas de cada área: i) Em Bocaina de Minas, onde foram encontradas 212 espécies, a elevada riqueza pode ser explicada por ser um remanescente com matriz vegetacional de Floresta Ombrófila Densa (FOD), fitofisionomia que normalmente apresenta alta riqueza, associada à altitude que, para florestas da Região Sudeste, mais próximas ao Equador que as da Região Sul, não parece estar ocasionando um ambiente tão limitante, provavelmente possibilitando a ocorrência de espécies de patamares mais baixos da FOD; ii) Em Carrancas, onde foram encontradas 211 espécies, a 


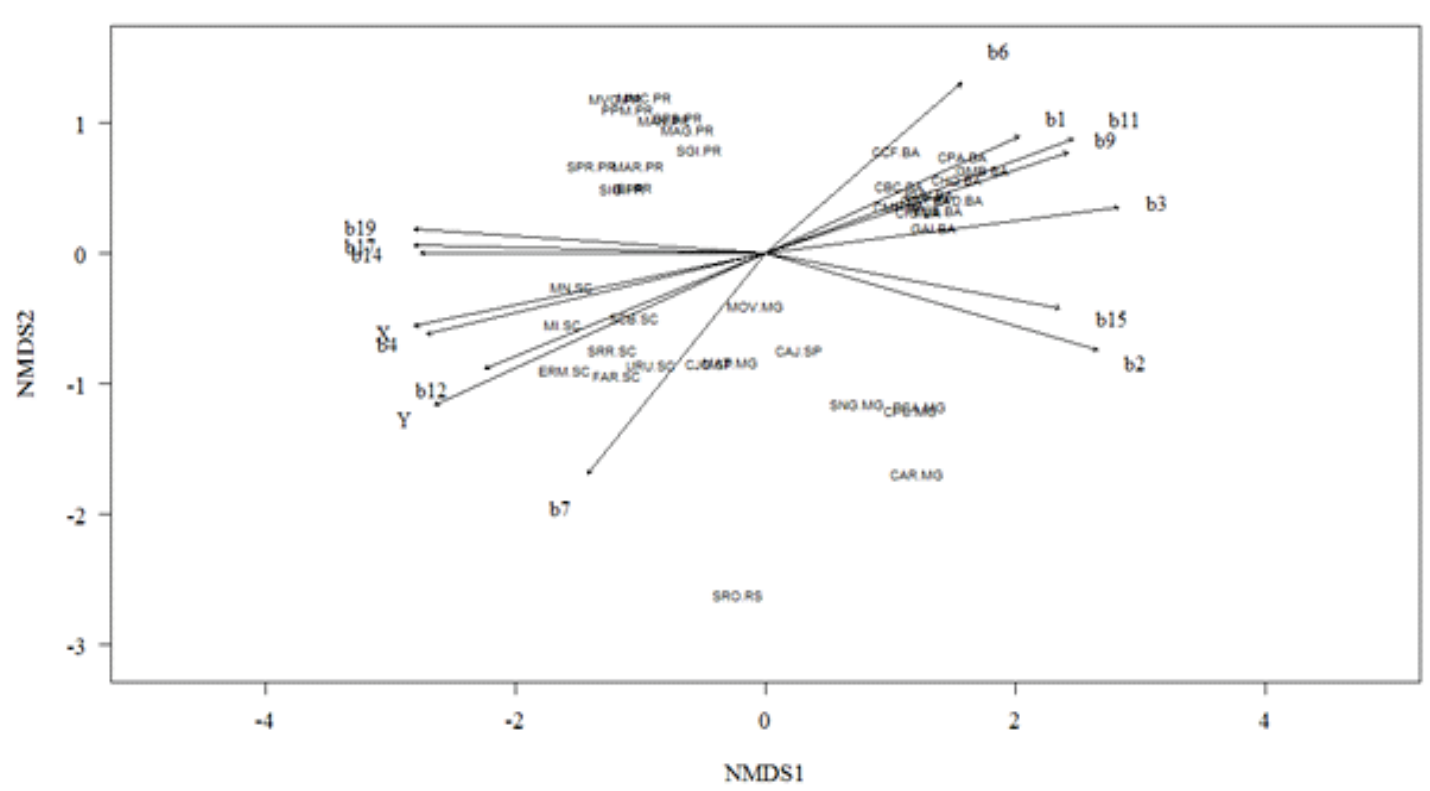

Figura 3 - Diagrama de ordenação produzido pela análise NMDS (Escalonamento multidimensional não métrico) de remanescentes de florestas superomontanas localizados no domínio atlântico, Brasil. O significado das siglas das áreas estudadas encontrase na Tabela 1. b1 = temperatura média anual; b2 = média da amplitude térmica diária; b3 = isotermalidade; b4 = sazonalidade térmica; b6 = temperatura mínima no mês mais frio; b7 = amplitude térmica anual; b9 = temperatura média no trimestre mais úmido; b11 = temperatura média no trimestre mais frio; b12 = precipitação total anual; b14 = precipitação no mês mais seco; b15 = sazonalidade da precipitação; b17 = precipitação total no trimestre mais seco; b19 = precipitação total no trimestre mais frio; $\mathrm{X}=$ longitude (graus); e $\mathrm{Y}=$ latitude (graus).

Figure 3 - Ordination diagram produced by NMDS (Nonmetric multidimensional scaling) analysis of upper montane forest fragments in Atlantic domain, Brazil. The abbreviations of the studied areas are in Table 1. b1 = annual mean temperature; $b 2=$ mean diurnal temperature range; $b 3=$ isothermality; $b 4=$ temperature seasonality; $b 6=$ minimum temperature of the coldest month; $b 7=$ annual temperature range; $b 9=$ mean temperature of the most humid quarter; b11 = mean temperature of the coldest quarter; b12 = annual precipitation; b14 = precipitation of the driest month; $b 15$ = precipitation seasonality; $b 17=$ precipitation of the driest quarter; $b 19=$ precipitation of the coldest quarter; $X=$ longitude (degrees); and $Y=$ latitude (degrees).

maior riqueza pode estar relacionada ao fato de esta ser uma região de ecótono entre a Floresta Atlântica (Floresta Semidecídua) e o Cerrado, possuindo, dessa forma, espécies das duas fitofisionomias. Além disso, na amostragem dessa área foram considerados diferentes micro-hábitats, como áreas próximas ao curso d’água e a encostas, o que também pode contribuir com o aumento da riqueza; iii) Em Poços de Caldas, onde foram encontradas 174 espécies, foi amostrado um gradiente altitudinal (1.200 a $1.575 \mathrm{~m}$ ), o que pode explicar a maior riqueza, visto que é possível encontrar espécies que ocorrem em diferentes faixas de altitude.

Entre as espécies mais abundantes nas florestas superomontanas estudadas, I. microdonta, C. scabra e D. brasiliensis já foram citadas como típicas dessa formação por Webster (1995) e Scheer e Mocochinski
(2009). Entretanto, espécies como B. salicifolius, $M$. umbellata, $P$. myrtifolia e C. canjerana, por exemplo, também são encontradas em pisos altitudinais mais baixos, podendo indicar maior plasticidade destas, possibilitando o avanço da ocorrência e do estabelecimento no patamar superomontano.

Mesmo com espécies comuns entre as florestas estudadas, a dissimilaridade entre algumas foi alta, possibilitando a formação de grupos distintos. A área do RS possui elevada dissimilaridade com os remanescentes de florestas ombrófilas explicada pela grande influência que essa recebe das florestas estacionais, ocorrendo espécies típicas estacionais, como Helietta apiculata Benth. e Myracrodruon balansae (Engl.) Santin. Portanto, a área está em uma região de transição, possuindo espécies típicas da 
Floresta Ombrófila Mista, mas, também, da Floresta Estacional Decidual. Já a dissimilaridade da área do RS com os demais remanescentes de florestas em matrizes estacionais pode ser explicada pelo fato desta fazer parte da Bacia do Alto Uruguai, no núcleo das Missiones, enquanto os demais remanescentes em matrizes estacionais fazerem parte do núcleo da Caatinga (BA) ou da Bacia do Alto Rio Grande (MG), também no núcleo das Missiones, mas em bacia hidrográfica distinta. De acordo com Prado e Gibbs (1993), na América do Sul as florestas estacionais estão separadas em núcleos, que estão distribuídos em forma de um arco, o chamado Arco do Pleistoceno, sendo os dois principais o núcleo da Caatinga, situado no Nordeste brasileiro, e o núcleo das Missiones, localizado, no Brasil, em partes das Regiões Sul, Sudeste e Centro-Oeste. Dessa forma, os remanescentes do grupo das florestas que estão em matrizes estacionais (BA e alguns remanescentes de MG, embora RS também esteja sob influência) estão em um desses núcleos.

O núcleo da Caatinga está representado pelos remanescentes da BA, que apresentaram grande similaridade florística entre si, sobretudo por estarem muito próximos geograficamente. Esses remanescentes possuem, no entanto, grande influência da flora arbórea de florestas úmidas (NASCIMENTO et al., 2010) (Bacia do Rio São Francisco/trecho Leste da Bacia Hidrográfica do Atlântico Sul) e são considerados como relictuais dessas florestas. Porém, mesmo com elementos de florestas úmidas, essas áreas estão em matrizes estacionais, com clima estacional, e possuem, também, espécies típicas de áreas estacionais, como Byrsonima stannardii W.R. Anderson e Cinnamomum haussknechtii (Mez) Kosterm.

O núcleo das Missiones está representado por áreas do Alto Rio Grande (MG) (Bacia do Rio Paraná) e também influencia a área do Alto Uruguai (RS) (Bacia do Rio Uruguai), que, no entanto, nas ordenações foram bastante dissimilares. A dissimilaridade que se observa entre fragmentos localizados em bacias hidrográficas distintas indica que a rede hidrográfica é fator importante na conectividade da paisagem, onde as matas ciliares atuam na interligação das áreas e possibilitam a movimentação de espécies da flora e da fauna. Outros autores, como Silva et al. (2007) e Higuchi et al. (2012), também encontraram maiores dissimilaridades florísticas entre bacias hidrográfica distintas, reforçando a ideia de que estas funcionam como unidades ambientais.
As áreas em matrizes Ombrófilas foram separadas, primeiramente, em grupos de florestas densas (áreas do PR) e predominantemente mistas (áreas de SC, SP e MG-Camanducaia). A Floresta Ombrófila Mista (FOM) dos fragmentos de SC e SP é considerada uma formação mais antiga, que possui presença marcante de Araucaria angustifolia (Bertol.) Kuntze. e onde coexistem representantes das floras tropical (afro-brasileira) e temperada (austro-brasileira), com elementos de Coniferales e Laurales (LEITE; KLEIN, 1990). Embora não tenha sido observada a presença de A. angustifolia nos remanescentes de MG (Camanducaia), foram encontradas outras espécies características da FOM, como Ilex paraguariensis A.St.-Hil., Ilex dumosa Reissek e Ocotea puberula (Rich.) Ness, indicando que esta é uma área transicional e justificando sua maior similaridade com as áreas de FOM.

As variáveis climáticas encontradas com maiores valores no grupo das florestas ombrófilas corroboram as definições dadas a essa formação, que é encontrada em áreas de clima úmido, com precipitação elevada e bem distribuída durante o ano (LEITE; KLEIN, 1990; IBGE, 2012; IVANAUSKAS; ASSIS, 2012). Além disso, são remanescentes com maior amplitude térmica anual e sazonalidade térmica, influenciados pela maior latitude, já que a maioria dos remanescentes deste estudo está localizada na Região Sul do Brasil.

No caso das florestas em matrizes estacionais, os resultados também confirmam os padrões encontrados nesse tipo vegetacional, que são caracterizados por estações climáticas bem definidas, com sazonalidade marcante da precipitação (IVANAUSKAS; ASSIS, 2012). Essa sazonalidade também é observada, de forma indireta, nos maiores valores de amplitude térmica diária, o que sugere menor umidade relativa do ar. Destacam-se, também, as mais altas temperaturas, o que pode estar sendo influenciado pela menor latitude.

A distribuição da vegetação em resposta às variações climáticas vem sendo verificada em todo o mundo (PAYETTE et al., 1985; PASTOR; POST, 1986; DYE, 1996; BONAN, 2008). Oliveira Filho et al. (2005) enfatizaram que os padrões relacionados ao clima e a formações vegetais sugerem que as variáveis climáticas, principalmente a temperatura e disponibilidade de água, tiveram longa influência na evolução e especiação das espécies no Leste da América do Sul, sendo esses os principais fatores que determinam a distribuição das formações vegetais ao longo do globo terrestre. 


\section{CONCLUSÃO}

Foi possível verificar que as áreas de floresta superomontana estudadas, de forma geral, sofrem influência da matriz florística em que estão inseridas, e os remanescentes localizados em uma mesma unidade fitogeográfica ficaram, predominantemente, agrupados. Os fragmentos podem ser classificados em: i) Áreas de Floresta Ombrófila Densa, onde foram localizados os fragmentos do PR; ii) Áreas de Floresta Ombrófila Mista ou com grande influência dessa fitofisionomia, onde foram localizados os remanescentes de SC, SP e MG (Camanducaia); iii) Áreas em matriz estacional (núcleo da Caatinga), mas com grande influência da vegetação de florestas úmidas, contendo os fragmentos da BA; e iv) Áreas de Florestas Estacionais ou com influência estacional do núcleo Missiones, onde foram localizados os demais remanescentes de MG (com altitudes inferiores a $1.900 \mathrm{~m}$ ). O remanescente do RS apresentou composição florística com alta dissimilaridade dos demais, não fazendo parte de nenhum agrupamento, em função da influência de elementos florísticos típicos da Bacia do Alto Uruguai, no núcleo das Missiones.

As variáveis ambientais mais correlacionadas com o gradiente ambiental encontrado foram as relacionadas à latitude e amplitude térmica anual, sendo essas maiores nos Estados do Sul do Brasil; e à precipitação, mais abundante nos Estados do Sul e com maior sazonalidade nos remanescentes com matrizes estacionais.

\section{REFERÊNCIAS}

BONAN, G. B. Forests and climate change: forcings, feedbacks, and the climate benefits of forests. Science, v.320, n.5882, p.1444-1449, 2008.

CARVALHO, D. A. et al. Variações florísticas e estruturais do componente arbóreo de uma floresta ombrófila alto-montana às margens do rio Grande, Bocaina de Minas, MG, Brasil. Acta Botanica Brasilica, v.19, n.1, p.91-109, 2005.

CONVENÇÃO PARAADIVERSIDADE BIOLÓGICA - CBD. Convention on Biological Diversity. Nações Unidas, 1992.

COSTA, M. P. et al. Estrutura e diversidade da comunidade arbórea de uma Floresta Superomontana, no Planalto de Poços de Caldas (MG). Ciência Florestal, v.21, n.4, p.711-725, 2011.
DAUBER, J. et al. Landscape structure as an indicator of biodiversity: matrix effects on species richness. Agriculture, Ecosystems and Environment, v.98, n.1-3, p.321-329, 2003.

DYE, P. J. Climate, forest and stream flow relationships in South African afforested catchments. Commonwealth Forestry, v.75, n.1, p.31-38, 1996.

ESKUCHE, U. El bosque de Araucaria com Podocarpus y los campos de Bom Jardim da Serra, Santa Catarina (Brasil meridional). Boletín de La Sociedad Argentina de Botánica, v.42, n.3-4, p.295-308, 2007.

FALKENBERG, D. Matinhas nebulares e vegetação rupícola dos Aparados da Serra Geral (SC/RS), sul do Brasil. 2003. 558f. Tese (Doutorado em Biologia Vegetal) Universidade Estadual de Campinas, Campinas, 2003.

FALKENBERG, D. B.; VOLTOLINI, J. C. The montane cloud forest in Southern Brazil. In: HAMILTON, L. S. et al. (Ed.) Tropical montane cloud forests. New York: SpringerVerlag, 1995. p.138-149.

FRANÇA, G. S.; STEHMANN, J. R. Composição florística e estrutura do componente arbóreo de uma floresta altimontana no município de Camanducaia, Minas Gerais, Brasil. Revista Brasileira de Botânica, v.27, n.1, p.19-30, 2004.

HIGUCHI, P. et al. Floristic composition and phytogeography of the tree component of Araucaria Forest fragments in southern Brazil. Brazilian Journal of Botany, v.35, n.2, p.145-157, 2012.

HIGUCHI, P. et al. Florística e estrutura do componente arbóreo e análise ambiental de um fragmento de Floresta Ombrófila Mista Altomontana no município de Painel, SC. Ciência Florestal, v.23, n.1, p.153-164, 2013.

HIJMANS, R. et al. Very high resolution interpolated climate surfaces for global land areas. International Journal of Climatology, v.25, n.15, p.1965-1978, 2005.

Revista Árvore, Viçosa-MG, v.38, n.5, p.787-797, 2014 
FUNDAÇÃO INSTITUTO BRASILEIRO DE GEOGRAFIA E ESTATÍSTICA - IBGE. Manual técnico da vegetação brasileira. Rio de Janeiro: 2012. 323p.

IVANAUSKAS, N. M.; ASSIS, M. C. Formações florestais brasileiras. In: MARTINS, S. V. (Ed.). Ecologia de florestas tropicais do Brasil. 2 ed. Viçosa, MG: Universidade Federal de Viçosa, 2012. p.252-293.

KOEHLER, A. et al. Floresta Ombrófila Densa Altomontana: aspectos florísticos e estruturais de diferentes trechos na Serra do Mar, PR. Ciência Florestal, v.12, n.2, p.27-39, 2002.

LEITE, P. F.; KLEIN, R. M. Vegetação. In: INSTITUTO BRASILEIRO DE GEOGRAFIA E ESTATÍSTICA - IBGE. (Ed.). Geografia do Brasil: Região Sul. Rio de Janeiro: 1990. v.2. p.113-150.

LISTA DE ESPÉCIES DA FLORA DO BRASIL. Disponível em: <http://floradobrasil.jbrj.gov.br> Acesso em: 12 jan. de 2013.

MARTINS-RAMOS, D. et al. Florística de Floresta Ombrófila Mista Altomontana e de Campos em Urupema, Santa Catarina, Brasil. Revista Brasileira de Biociências, v.9, n.2, p.156-166, 2010.

MEIRELES, L. D. et al. Variações na composição florística e na estrutura fitossociológica de uma floresta ombrófila densa alto-montana na Serra da Mantiqueira, Monte Verde, MG. Revista Brasileira de Botânica, v.31, n.4, p.559-574, 2008.

MINCHIN, P. An evaluation of the relative robustness of techniques for ecological ordination. Plant Ecology, v.69, n.1-3, p.89107, 1987.

NASCIMENTO, F. H. F. et al. Diversidade arbórea das florestas alto montanas no Sul da Chapada Diamantina, Bahia, Brasil. Acta Botânica Brasilica, v.24, n.3, p.674-685, 2010.

OKSANEN, J. et al. Vegan: community ecology package. R package version, v.1. p.8. 2009.

Revista Árvore, Viçosa-MG, v.38, n.5, p.787-797, 2014
OLIVEIRA FILHO, A. T. et al. Variações estruturais do compartimento arbóreo de uma floresta semidecídua alto-montana na chapada das Perdizes, Carrancas, MG. Revista Brasileira de Botânica, v.27, n.2, p.291309, 2004.

OLIVEIRA FILHO, A. T. et al. Floristic relationships of seasonally dry forests of eastern South America based on tree species distribution patterns. In: PENNINGTON, R. T. et al. (Ed.). Neotropical savannas and dry forests: plant diversity, biogeograpgy and conservation. Boca Raton: CRC Press, 2005. p.151-184.

OLIVEIRA FILHO, A. T. Classificação das fitofisionomias da América do Sul cisandina tropical e subtropical: proposta de um novo sistema - prático e flexível - ou uma injeção a mais de caos? Rodriguésia, v.60, n.2, p.237-258, 2009.

PASTOR, J.; POST, W. M. Influence of climate, soil moisture, and succession on forest carbon and nitrogen cycles. Biogeochemistry, v.2, n.1, p.3-27, 1986.

PAYETTE, S. et al. Secular climate change in oldgrowth tree-line vegetation of northern Quebec. Nature, v.315, n.6015, p.135-138, 1985.

PEREIRA-SILVA, E. F. L. et al. Caracterização florística da vegetação lenhosa de um fragmento urbano de Floresta Ombrófila Mista Altomontana, Campos do Jordão, SP. Holos Environment, v.7, n.2, p.156-166, 2007.

PORTES, M. C. G. O. et al. Caracterização florística e estrutural de uma Floresta Ombrófila Densa Altomontana do morro do Anhangava, Quatro Barras - PR. Revista Floresta, v.31, n.1/2, p.9-18, 2001.

PRADO, D. E.; GIBBS, P. E. Patterns of species distributions in the dry seasonal forests of South America. Annals of the Missouri Botanical Garden, v.80, n.1, p.902-927, 1993.

R DEVELOPMENT CORE TEAM. R: A language and environment for statistical computing. R Foundation for Statistical Computing, 2010. Disponível em: <http://www.R-project.org> Acesso em: 15 dez. de 2012. 
RIBAS, R. F. et al. Composição florística de dois trechos em diferentes etapas serais de uma Floresta Estacional Semidecidual em Viçosa, Minas Gerais. Revista Árvore, v.27, n.6, p.821-830, 2003.

ROCHA, M. R. L. Caracterização

fitossociológica e pedológica de uma

Floresta Ombrófila Densa

Altomontana no Parque Estadual

Pico do Marumbi - Morretes, PR.1999.

81f. Dissertação (Mestrado em Engenharia

Florestal) - Universidade Federal do Paraná,

Curitiba, 1999.

RODERJAN, C. V. A Floresta Ombrófila

Densa Altomontana no Morro

Anhangava, Quatro Barras, PR -

aspectos climáticos, pedológicos e

fitossociológicos. 1994. 119f. Tese

(Doutorado em Engenharia Florestal) -

Universidade Federal do Paraná, Curitiba, 1994.

SCHEER, M. B.; MOCOCHINSKI, A. Y. Florística vascular da Floresta Ombrófila Densa

Altomontana de quatro serras no Paraná. Biota

Neotropica, v.9, n.2, p.51-70, 2009.
SILVA, A. C. et al. Comparação florística de florestas inundáveis das regiões Sudeste e Sul do Brasil. Revista Brasileira de Botânica, v.30, n.2, p.257-269, 2007.

VALENTE, A. S. M. et al. Composição, estrutura e similaridade florística da Floresta Atlântica, na Serra Negra, Rio Preto - MG. Rodriguésia, v.62, n.2, p.321-340, 2011.

VALERIANO, D. D. B. Dinâmica da

Floresta Ombrófila Mista Alto

Montana, Campos do Jordão, SP. 2010.

198f. Tese (Doutorado em Ciências) -

Universidade de São Paulo, São Paulo, 2010.

van den BERG, E.; OLIVEIRA FILHO, A. T.

Composição florística e estrutura fitossociológica de uma floresta ripária em Itutinga, MG, e comparação com outras áreas. Revista Brasileira de Botânica, v.23, n.3, p.231-253, 2000.

WEBSTER, G. L. The panorama of Neotropical cloud forests. In: CHURCHILL, S. P. et al. (Ed.) Biodiversity and conservation of Neotropical Montane Forests. New York: The New York Botanical Garden, 1995. p.53-77. 